\title{
Mechanistic insight on the activity and substrate selectivity of nonheme iron dioxygenases
}

DOI:

10.1002/tcr.201800033

\section{Document Version}

Accepted author manuscript

Link to publication record in Manchester Research Explorer

\section{Citation for published version (APA):}

De Visser, S. (2018). Mechanistic insight on the activity and substrate selectivity of nonheme iron dioxygenases. Chemical Records, 18(10), 1501-1516. https://doi.org/10.1002/tcr.201800033

\section{Published in:}

Chemical Records

\section{Citing this paper}

Please note that where the full-text provided on Manchester Research Explorer is the Author Accepted Manuscript or Proof version this may differ from the final Published version. If citing, it is advised that you check and use the publisher's definitive version.

\section{General rights}

Copyright and moral rights for the publications made accessible in the Research Explorer are retained by the authors and/or other copyright owners and it is a condition of accessing publications that users recognise and abide by the legal requirements associated with these rights.

\section{Takedown policy}

If you believe that this document breaches copyright please refer to the University of Manchester's Takedown Procedures [http://man.ac.uk/04Y6Bo] or contact uml.scholarlycommunications@manchester.ac.uk providing relevant details, so we can investigate your claim.

\section{OPEN ACCESS}


Mechanistic insight on the activity and substrate selectivity of nonheme iron dioxygenases

Sam P. de Visser ${ }^{*[a]}$

[a] Dr S.P. de Visser
The Manchester Institute of Biotechnology and School of Chemical
Engineering and Analytical Science

Engineering and Analytical Science

131 Princess Street, Manchester, M1 7DN, United Kingdom.

sam.devisser@manchester.ac.uk

See last page for Frontipiece 
Abstract: Nonheme iron dioxygenases catalyze vital reactions for human health particularly related to aging processes. They are involved in the biosynthesis of amino acids, but also the biodegradation of toxic compounds. Typically they react with substrate through oxygen atom transfer, although often with the assistance of a co-substrate like $\alpha$-ketoglutarate that is converted to succinate and $\mathrm{CO}_{2}$. Many reaction processes catalyzed by the nonheme iron dioxygenases are stereoselective or regiospecific and hence understanding the mechanism and protein involvement in the selectivity is important for the design of biotechnological applications of these enzymes. In this Account I will review recent work of our group on nonheme iron dioxygenases and include background information on their general structure and catalytic cycle. Examples of stereoselective and regiospecific reaction mechanisms we elucidated are for the AlkB repair enzyme, prolyl-4-hydroxylase and the ergothioneine biosynthesis enzyme. Finally, I cover an example where we bioengineered S-phydroxymandelate synthase into the R-p-hydroxymandelate synthase.

\section{Introduction}

Iron is the most common transition metal on earth and hence many natural processes utilize an iron active site. Mononuclear iron in nature is bound to proteins either in a heme macrocyclic ligand or through direct interactions with amino acid side chains in a nonheme iron environment. ${ }^{[1,2]}$ Heme proteins are versatile groups of enzymes with a large variety of chemical and biological functions. Thus, the cytochromes P450 are heme monoxygenases, where the metal is linked to the protein via a thiolate bridge of a cysteinate residue..$^{[1,3]}$ Their functions are typically in the liver where they initiate the biodegradation of metabolites as well as the biosynthesis of essential hormones. By contrast, heme peroxidases link the heme to the protein via a histidine linkage and reduce $\mathrm{H}_{2} \mathrm{O}_{2}$ substrate to two water molecules ${ }^{[4]}$ whereas the heme catalases usually have a tyrosinate axial ligand and convert $\mathrm{H}_{2} \mathrm{O}_{2}$ to molecular oxygen and water. ${ }^{[5]}$ As heme is a tetradentate ligand, the heme iron systems typically have five ligand positions of the metal occupied and the sixth ligand position is reserved for molecular oxygen (or hydrogen peroxide). Hence substrates cannot bind the metal directly and are activated in the vicinity of the heme group.

A large class of mononuclear iron enzymes lacks the heme ligand system and binds the metal directly to the protein, and consequently is called the nonheme iron enzymes. ${ }^{[2]}$ Thus, in nonheme iron dioxygenases, by contrast to the heme monoxygenases, peroxidases and catalases, the metal binds the protein via usually three amino acid side chains. The most common ligand features of nonheme iron dioxygenases is

[a] Dr S.P. de Visse

Manchester Institute of Biotechnology and School of Chemical Engineering and Analytical Science

The University of Manchester

131 Princess Street, Manchester M1 7DN (United Kingdom)

E-mail: sam.devisser@manchester.ac.uk binding of the iron to two histidine and one carboxylate group of either an Asp or Glu residue as a 2-His/1-carboxylate facial orientation. As such that leaves three ligand positions of the metal open, where substrate, co-substrate and dioxygen can bind. Although in some nonheme iron dioxygenases the substrate binds the metal directly this is not the case for all of them. Hence, there is a large variety in substrate binding as well as metal coordination environment in nonheme iron dioxygenases and consequently in reactivity patterns with substrates. Interestingly, several of these enzymes catalyze a stereoselective or regiospecific reaction mechanism and their origins are still poorly understood.

To understand how enzymes react with substrates and what the effect of the protein environment is on the catalytic reaction mechanism as well as the origin of the stereo- and regioselectivity of product formation, many computational studies have been performed. ${ }^{\left[{ }^{[6]}\right.}$ In our group, we studied enzymatic reaction mechanisms computationally using active site models as well as quantum mechanics/molecular mechanics (QM/MM) on full enzymatic systems. ${ }^{[7]}$ Our work has given insight into the intricate details of fast reaction mechanisms within an enzyme and identifies the active oxidant and the rate determining step in the reaction mechanism. Moreover, in several enzymes the reaction is stereoselective and/or regiospecific and sometimes even a thermochemically unfavorable reaction is catalyzed. Computational modelling assists with the understanding of reaction mechanisms and can even be used to predict changes in product distributions upon active site mutations. As such computational modelling is an important tool in chemical biology that often is performed alongside experimental studies. In this Account I will review recent highlights from our group on understanding the mechanism and activity of nonheme iron dioxygenases and also give an example how we bioengineered a nonheme iron dioxygenase and changed its catalytic function and product distributions.

De Visser is a Reader in Computational Biocatalysis at the University of Manchester and has been based in the Manchester Institute of Biotechnology since 2004. His research interests are in the field of Inorganic Reaction Mechanisms and Computational Chemistry. The research of the de Visser group is mainly focused on the understanding of biological and biomimetic transition metal containing systems. His group uses a combination of density functional theory methods on model systems and quantum mechanics/molecular mechanics on enzyme structures. Key research areas investigated by the de Visse group cover the mechanistic features and substrate activation of the cytochromes P450 and nonheme iron dioxygenases and halogenases. Over the years, de Visser has published close to 200 publications in range of scientific journals. 


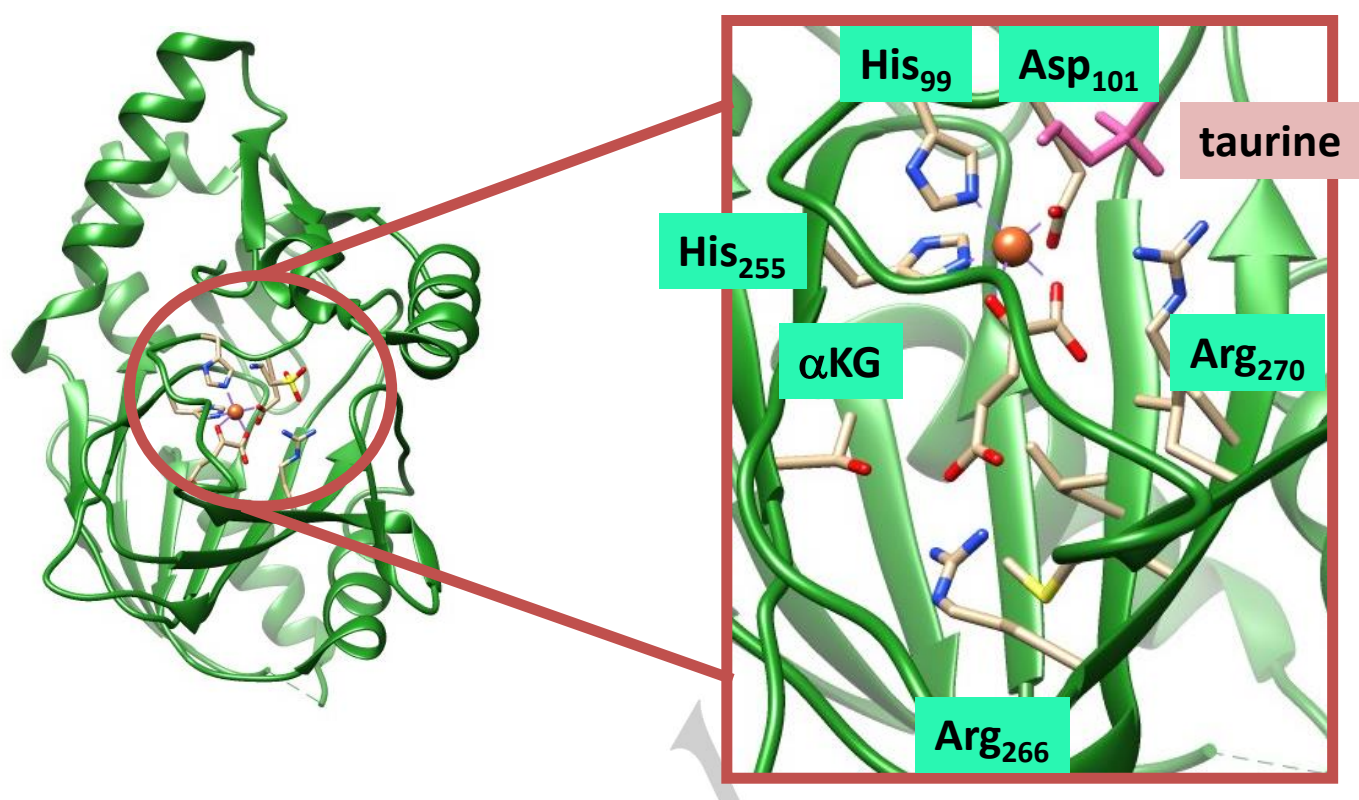

Figure 1. Crystal structure coordinates (1GQW pdb file) of taurine/ $\alpha \mathrm{KG}$ dependent dioxygenase with active site structure highlighted.

\section{Nonheme iron dioxygenases}

Although nonheme iron dioxygenases have been reviewed in detail previously, ${ }^{[1 d, 2]}$ I will start this Account with a short description of the typical features of their structure and reactivity and give a general overview on the consensus catalytic cycle. These nonheme iron dioxygenases participate in vital reaction processes in the human body related to biosynthesis and biodegradation. Thus, one of the most common amino acids in collagen is 4-hydroxyproline, which is synthesized in the body from proline by the nonheme iron dioxygenase prolyl-4hydroxylase. ${ }^{[8]}$ Its biochemical function in the body is, therefore, related to aging and hence understanding its catalytic mechanism is relevant for human health.

Another nonheme iron dioxygenase with big relevance for human health is cysteine dioxygenase (CDO) ${ }^{[9]}$ which catalyzes the first step in the catabolism of cysteine. Thus, cysteine is a toxic amino acid at high concentrations that is synthesized in the body from methionine. At elevated concentrations, cysteine is believed to lead to neurodegenerative diseases such as Alzheimer's and Parkinson's diseases. Therefore, the body has biodegradation machinery in action that metabolizes cysteine to keep its concentration within acceptable levels. This process starts with $\mathrm{CDO}$ that converts cysteinate into cysteine sulfinic acid on an iron center using one molecule of $\mathrm{O}_{2}{ }^{\left[{ }^{[9]}\right.}$ In subsequent steps, cysteine sulfinic acid is oxidized to cysteic acid and decarboxylated to form taurine. Another nonheme iron dioxygenase, taurine/ $\alpha$-ketoglutarate ( $\alpha \mathrm{KG}$ ) dioxygenase (TauD) takes taurine as a substrate and hydroxylates it at the $C^{2}$ position, which thereafter leads to dissociation of sulfate from the product. ${ }^{[10]}$

Clearly, the human body contains a large array of nonheme iron dioxygenases with important functions for human health. In the past few decades many structures of nonheme iron enzymes have been deposited at the protein data bank, ${ }^{[11]}$ which enables detailed computational studies on their mechanism and reactivity. As mentioned above, the nonheme iron dioxygenases lack an organic cofactor, such as a heme and bind the protein directly. I will start, therefore, with a short summary of the typical features of the nonheme iron structure followed by a brief discussion on their catalytic cycle. More details can be found in earlier reviews on this topic. ${ }^{[1,2,2,12]}$ In the third chapter then several examples of recent computational studies from our group are given that focus on the regioselectivities of the rate-determining steps of the reaction mechanism.

\subsection{Structure}

In contrast to heme oxygenases and catalases, nonheme iron dioxygenases have the metal bound to the protein directly and usually through interactions with three amino acid side chains. Typically, these are from two histidine and one aspartic acid residue that give a facial 2-His/1-Asp orientation. An example of a nonheme iron dioxygenase active site structure and protein is given in Figure 1 for substrate and $\alpha$-ketoglutarate $(\alpha K G)$ bound taurine/ $\alpha \mathrm{KG}$ dependent dioxygenase (TauD) as taken from the $1 \mathrm{GQW}$ protein databank (pdb) file. ${ }^{[11,13]}$ As can be seen from Figure 1 the protein contains several $\alpha$-helices and $\beta$-pleated sheets and has the iron co-factor located in the inner core of the protein, well shielded from the surface. 


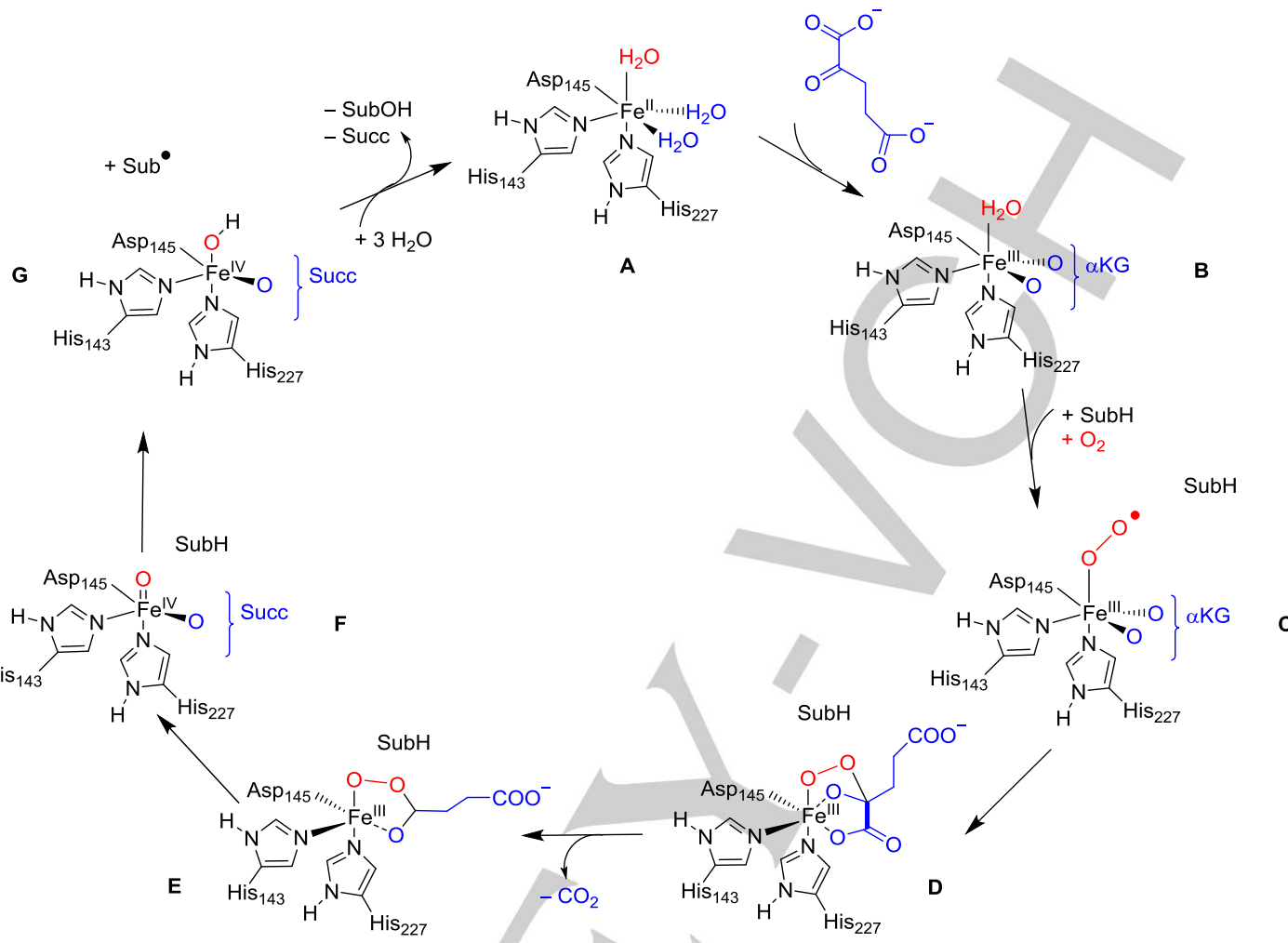

Figure 2. Consensus catalytic cycle of nonheme iron/aKG utilizing dioxygenases. SubH stands for substrate and the amino acid labelling is from TauD.

The iron binds the protein through the imidazole side chains of $\mathrm{His}_{99}$ and $\mathrm{His}_{255}$ and the carboxylate group of $\mathrm{Asp}_{101}$. In addition, $\alpha K G$ occupies two of the remaining ligand sites of the metal and binds via the carboxylate and $\alpha$-keto positions, whereas the other terminal carboxylic acid group is held in position through a salt bridge with $\operatorname{Arg}_{266}$. Consequently, $\alpha \mathrm{KG}$ is tightly bound in the pocket and held in position through hydrogen bonding and covalent interactions. The last ligand position of the metal is vacant in the $1 \mathrm{GQW}$ structure and will be occupied by molecular oxygen in a later stage of the catalytic cycle. Substrate taurine $\left(\mathrm{H}_{3} \mathrm{~N}^{+} \mathrm{CH}_{2} \mathrm{CH}_{2} \mathrm{SO}_{3}^{-}\right)$is bound in a pocket nearby the metal that is lined with a number of aromatic and polar residues, one of those is $\operatorname{Arg}_{270}$ that forms a salt bridge with the sulfate group.

\subsection{Catalytic cycle}

Many experimental and computational studies have focused on the intermediates in the catalytic cycle and for the enzyme taurine/ $\alpha \mathrm{KG}$ dioxygenase (TauD) a number of short-lived intermediates were experimentally trapped and characterized. ${ }^{[14]}$ As such TauD has become the template of nonheme iron dioxygenases research in general. Based on these spectroscopic and kinetics studies a catalytic cycle (Figure 2) was devised that has gained support from computational modelling. ${ }^{[15]}$ In general, all computational studies come to the same conclusion and support the experimental assignment.

The catalytic cycle starts from the resting state (structure $\mathbf{A}$ in Figure 2), which has the iron(II) bound to the protein via the typical 2-His/1-carboxylate motif and in TauD these ligands are $\mathrm{His}_{143}, \mathrm{Asp}_{145}$ and $\mathrm{His}_{227}$. The remaining three ligand positions are occupied with water molecules. Upon $\alpha \mathrm{KG}$ binding (structure

B) two waters are displaced and only the water molecule trans to $\mathrm{His}_{227}$ is left. Substrate (SubH) binding releases also this final water molecule and makes space for $\mathrm{O}_{2}$ to bind as an iron(III)superoxo complex (structure $\mathbf{C}$ ). This intermediate is short-lived and has never been detected, but computational modelling predicts the terminal oxygen atom to attack the $\alpha$-keto position of $\alpha \mathrm{KG}$ to form a bicyclic ring structure $\mathbf{D} .^{[15 a b]}$ Also structure $\mathbf{D}$ is short-lived and has weakened $\mathrm{C}-\mathrm{C}$ bond strength, so that it rapidly collapses to persuccinate through loss of $\mathrm{CO}_{2}$ (structure E). The subsequent dioxygen bond cleavage gives succinate and an iron(IV)-oxo species (structure $\mathbf{F}$ ), which has been spectroscopically characterized with resonance Raman, electron paramagnetic resonance and Mössbauer spectroscopy measurements. ${ }^{[14]}$ 


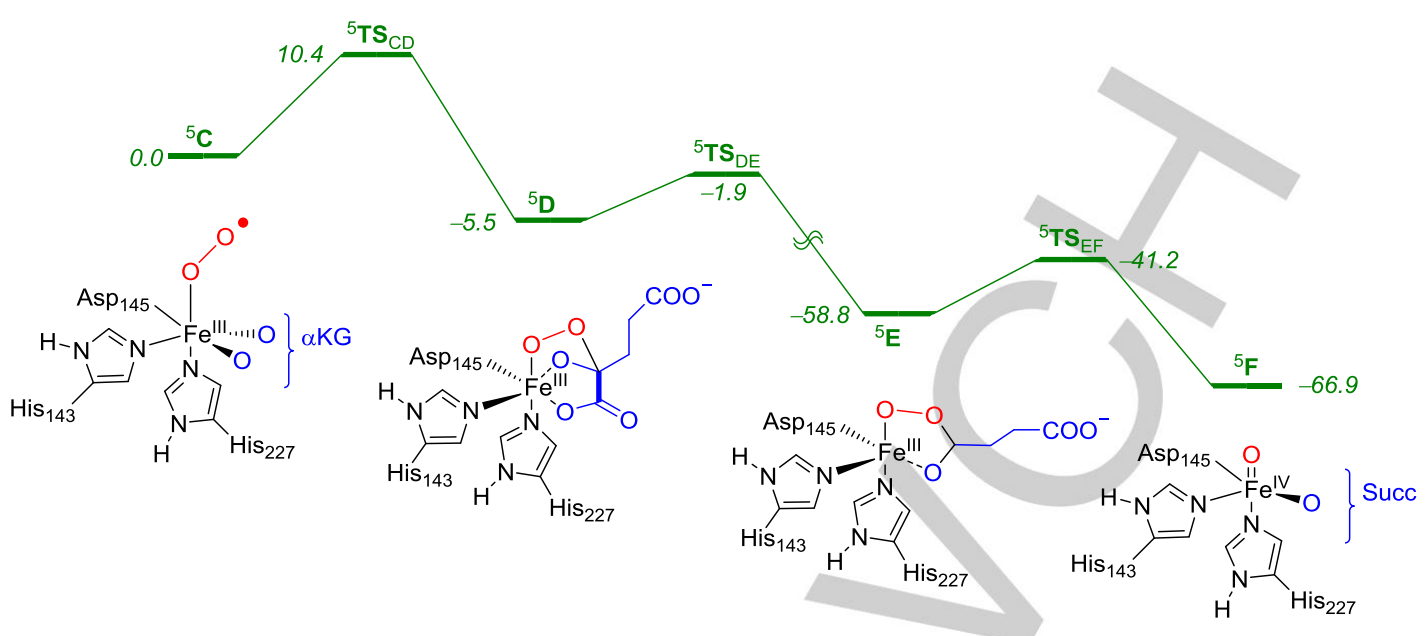

Figure 3. Potential energy landscape for the conversion of the iron(III)-superoxo species into the iron(IV)-oxo species. Labelling as in Figure 2 with energies calculated using a model complex in $\mathrm{kcal} \mathrm{mol}^{-1}$ with values taken from Ref ${ }^{[15 b]}$

In the final stage of the catalytic cycle the actual substrate (taurine) activation takes place through a hydrogen atom abstraction to form an iron(III)-hydroxo complex (structure $\mathbf{G}$ ) followed by $\mathrm{OH}$ rebound to form alcohol products. The alcoho product and succinate are released from the protein and the vacant iron ligand positions reoccupied with water molecules to close the catalytic cycle.

The potential energy profile for the quintet spin state of oxygen activation starting from the iron(III)-superoxo complex is shown in Figure 3 with data taken from Ref. ${ }^{[15 b]}$. A small activation energy via transition state $\left({ }^{5} \mathbf{T S}_{\mathrm{CD}}\right)$ of about $10.4 \mathrm{kcal} \mathrm{mol}^{-1}$ separates the iron(III)-superoxo from the bicyclic ring structure $\left({ }^{5} \mathbf{D}\right)$. However, this intermediate encounters only a small transition state $\left(2.6 \mathrm{kcal} \mathrm{mol}^{-1} \mathrm{via}^{5} \mathrm{TS} \mathrm{S}_{\mathrm{DE}}\right)$ for decarboxylation to form the persuccinate intermediate ${ }^{5} \mathrm{E}$ with large exothermicity. As such, the lifetimes of ${ }^{5} \mathbf{C}$ and ${ }^{5} \mathbf{D}$ are expected to be short and indeed no conclusive experimental evidence of these structures exists. The persuccinate structure cleaves the $\mathrm{O}-\mathrm{O}$ bond via barrier ${ }^{5} \mathbf{T S}_{\mathrm{EF}}$ to form the iron(IV)-oxo in another exothermic step. The latter was trapped and experimentally characterized and the modelling agreed well with the experimental assignments.

In the final stage, the iron(IV)-oxo picks up a hydrogen atom from taurine and rebounds the $\mathrm{OH}$ to form alcohol products. ${ }^{[16]}$ In many nonheme iron dioxygenases this process is stereoselective or regiospecific and in recent years we covered several computational studies on the nature of these selectivities which we will discuss in the next section of this Account.

\section{Computational modelling on the mechanism of nonheme iron dioxygenases}

In the following several examples from our own group are given with results of computational studies on the mechanisms of substrate activation by nonheme iron dioxygenases. All of these follow the consensus catalytic cycle of Figure 2, although with some minor tweaks and additions based on the specific reaction mechanism. However, in general the nonheme iron dioxygenases follow a catalytic cycle that is split into two stages: (1) formation of an iron(IV)-oxo species and (2) substrate activation by the iron(IV)-oxo species.

\subsection{Bioengineering of S-p-hydroxymandelate synthase into} R-p-hydroxymandelate synthase

The nonheme iron dioxygenase S-p-hydroxymandelate synthase performs an essential precursor step in the biosynthesis of vancomycin type antibiotics, ${ }^{[17]}$ whereby it converts $p$ hydroxyphenylpyruvate into S-p-hydroxymandelate enantio- and stereospecifically. The reaction takes place on a nonheme iron center with the use of one molecule of $\mathrm{O}_{2}$, Scheme 1 , and follows a catalytic cycle similar to that described above in Figure 2. However, since the substrate already contains an $\alpha$-keto acid moiety, no additional $\alpha K G$ co-substrate is needed and the $p$ hydroxyphenylpyruvate binds the iron directly through the $\alpha$-keto and carboxylate groups. Then the sole use of molecular oxygen on the iron center converts substrate into S-p-hydroxymandelate products.

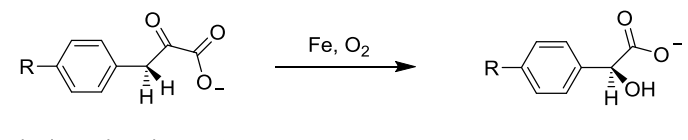

p-hydroxyphenylpyruvate

S-p-hydroxymandelate 


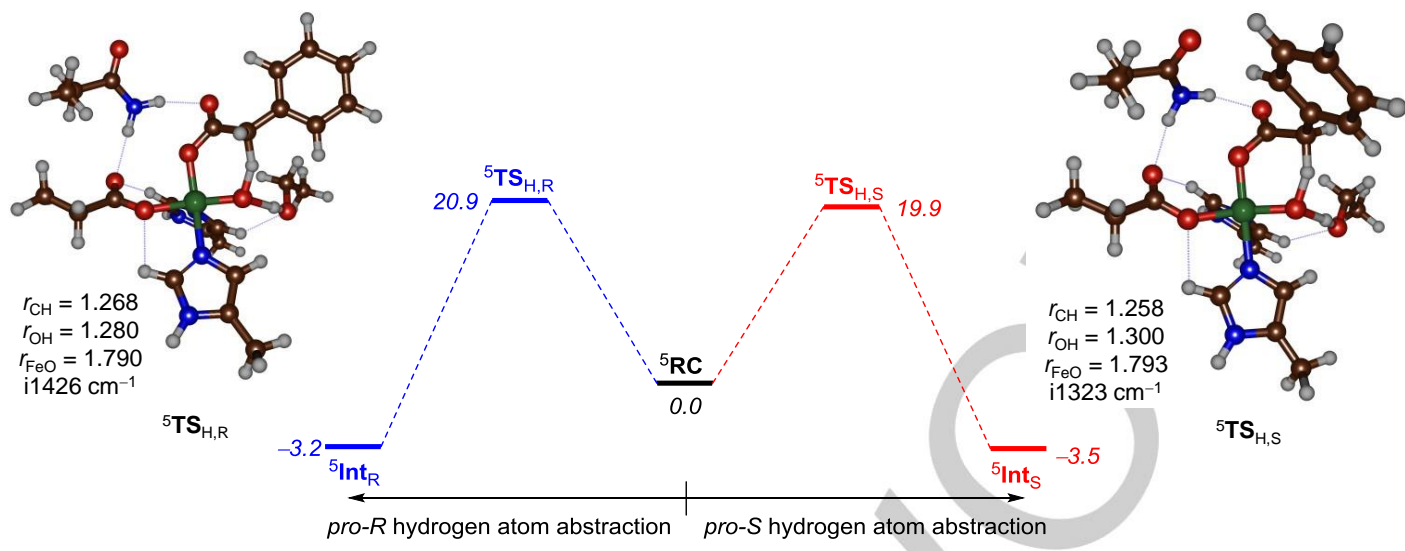

Figure 4. Calculated reaction pathways for hydrogen atom abstraction by an iron(IV)-oxo species from the pro-S and pro-R positions of 2-phenylacetate. Energies are in $\mathrm{kcal} \mathrm{mol}^{-1}$ and calculated at the $\triangle \mathrm{E}+\mathrm{ZPE}$ level of theory obtained at UB3LYP. Optimized geometries of the transition states give bond lengths in angstroms and the imaginary frequency in the transition state in $\mathrm{cm}^{-1}$.

As such the catalytic cycle starts with p-hydroxyphenylpyruvate and $\mathrm{O}_{2}$ binding to an iron center and the oxygen atom transfer to substrate followed by decarboxylation to form 2-phenyl-acetate and an iron(IV)-oxo species. Several computational and experimental studies have been reported on its catalytic mechanism. ${ }^{[18,19]}$ One key experimental result assigned a ratedetermining hydrogen atom abstraction step in the reaction performed by the iron(IV)-oxo intermediate, which was determined from kinetics studies by replacing the transferring hydrogen atom by deuterium. The rate constant change led to a significant kinetic isotope effect; therefore, the hydrogen atom abstraction is rate determining. ${ }^{[20}$

A p-hydroxymandelate bound crystal structure of the enzyme was reported that showed the metal to be bound to the typical 2 $\mathrm{His} / 1$-Glu ligand motif with the amino acids $\mathrm{His}_{151}, \mathrm{His}_{241}$ and Glu $_{320}{ }^{[21]}$ Although the substrate binding position is aligned with aromatic and aliphatic amino acid residues, also two polar residues $\left(\mathrm{Ser}_{201}\right.$ and $\mathrm{Thr}_{241}$ ) were identified and proposed to be involved in substrate positioning. The focus of our studies on this enzyme was to attempt to bioengineer the S-phydroxymandelate synthase into the R-p-hydroxymandelate synthase through active site mutations. A feat of this kind had never been succeeded before for a nonheme iron dioxygenase. The bioengineered protein; therefore, should give a complete enantioselectivity reversal in the reaction mechanism as compared to the wildtype structure.

The work started with a density functional theory (DFT) study on an active site model of S-p-hydroxymandelate synthase, whereby we selected the iron with its first coordination sphere ligands: imidazole groups for $\mathrm{His}_{151}$ and $\mathrm{His}_{241}$, propionate for $\mathrm{Glu}_{320}$, ethanol for $\mathrm{Ser}_{201}$, the terminal side chain of $\mathrm{Glu}_{305}$ and substrate 2-phenyl-acetate, see Figure $4 .{ }^{[22]}$ For the non-metal ligated groups constraints were used during the geometry optimization to keep them in the area they occupy in the crystal structure. We calculated the hydrogen atom abstraction of both hydrogen atoms from carbon atom $\mathrm{C}^{2}$ of the substrate that give the pro-R and pro-S hydrogen atom abstraction barriers $\left({ }^{5} \mathbf{T S}_{\mathrm{H}}\right)$ and intermediates $\left({ }^{5} \operatorname{lnt}\right)$. The obtained energy landscape of the gas-phase model is shown in Figure 4. In the gas-phase both pathways are close in energy as there are no protein perturbations that prevent one orientation over the other. Similarly, the driving force for hydrogen atom abstraction from the pro-R and pro-S positions is very close and so are their geometric features (insets of Figure 4) as expected from a gasphase model complex.

Subsequently, we took the optimized geometries of the quintet spin hydrogen atom abstraction transition states $\left({ }^{5} \mathbf{T S}_{H, R}\right.$ and ${ }^{5} \mathbf{T S}_{\mathrm{H}, \mathrm{S}}$ ) and inserted those structures back into the crystal structure coordinates. ${ }^{[22]}$ Obviously, the ${ }^{5} \mathbf{T S}_{\mathrm{H}, \mathrm{S}}$ structure fitted in neatly without major stereochemical repulsions of protein residues of the enzyme. By contrast, the pro- $R$ hydrogen atom abstraction barrier did not fit in and clashed with existing protein residues in the substrate binding pocket, which is not surprising as the enzyme is not supposed to proceed through this reaction pathway. We did then created enzyme mutants that (i) made space for the R-enantiomer to bind properly and (ii) blocked space for the S-enantiomer. Thus, based on the ideal binding position of ${ }^{5} \mathbf{T S}_{\mathrm{H}, \mathrm{R}}$ from the gas-phase DFT calculations we proposed a triple mutant structure that would be able to bind the pro-R substrate but not the pro-S hydrogen atom abstraction transition state, namely the Ser221Met/Val223Phe/Tyr359Ala triple mutant. In particular, the mutations at positions 221 and 223 fill up the space where the aromatic ring of the Senantiomer is normally positioned and prevents ideal binding of the S-orientation. On the other hand, the Tyr359Ala mutation makes space in the substrate binding pocket to bind the substrate into the preferred pro-R orientation.

Using the information from the computational modelling, a number of single, double and triple mutants were created for Sp-hydroxymandelate synthase in the laboratory including the Ser221Met/Val223Phe/Tyr359Ala triple mutant as proposed by the calculations. ${ }^{[22]}$ Subsequently, product distributions of S- and R-p-hydroxymandelate were measured. Indeed as predicted from the modelling, the triple mutant gives $>97 \%$ of the Renantiomer. 


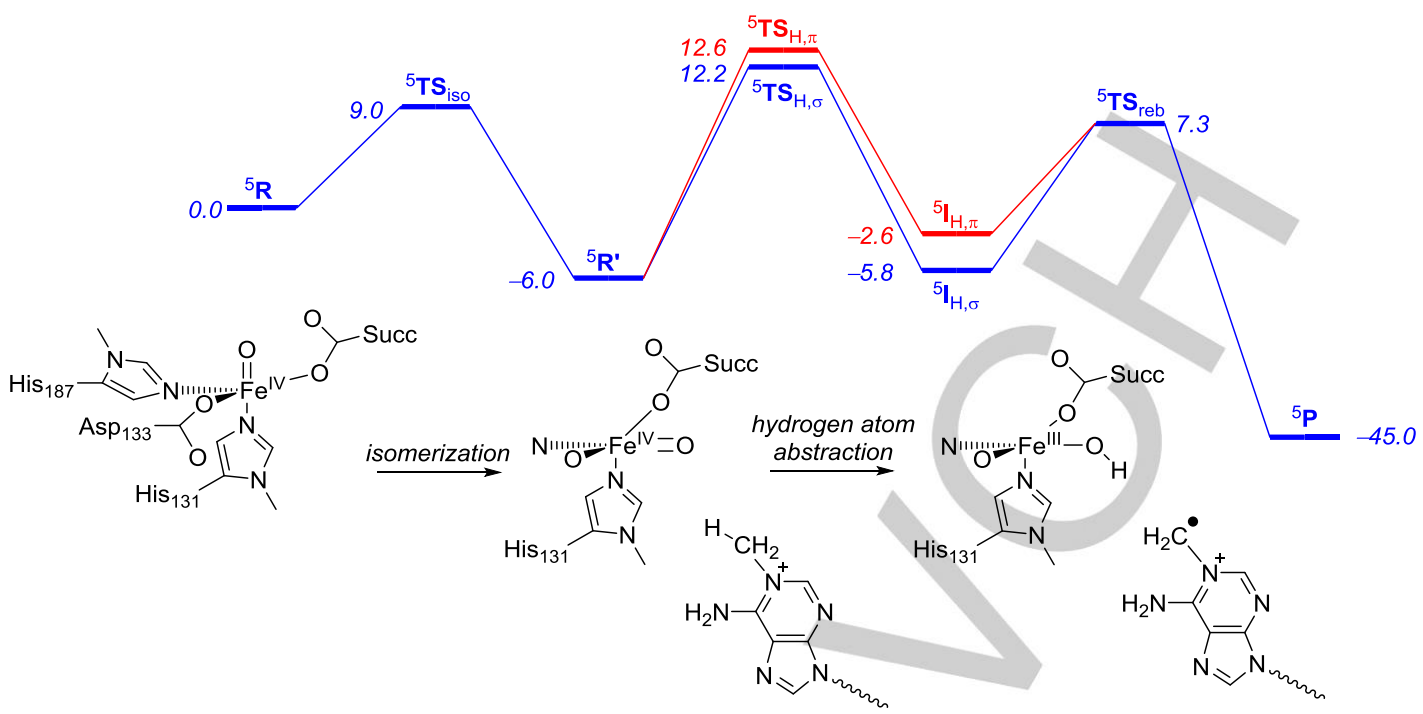

Figure 5. QM/MM derived reaction mechanism for the hydroxylation of methylated adenine residue by AlkB repair enzymes. Energies are in kcal mol ${ }^{-1}$ and calculated at the $\triangle \mathrm{E}+\mathrm{ZPE}$ level of theory obtained at UB3LYP.

Consequently, the computational modelling predicted how to bioengineer a nonheme iron dioxygenase and change its enantioselectivity of the reaction. To be specific, we converted S-p-hydroxymandelate synthase into R-p-hydroxymandelate synthase. This is the first example where a nonheme iron dioxygenase was bioengineered to obtain an enantioselectivity reversal.

\subsection{Mechanism of AlkB repair enzyme}

Nonheme iron enzymes with important functions for human health are the DNA and RNA repair enzymes called AlkB. ${ }^{[23]}$ These enzymes take alkylated DNA bases and through an alkyl hydroxylation and deformylation step revert them back to their original bases. Thus, during the DNA transcription the DNA bases of the mother strand are alkylated to prevent DNA polymerase damaging the original strand. In addition, chemical modification of DNA and RNA strands by reaction with chemicals, such as methylhalides or methylmethane sulfonate, lead to the formation of alkylated DNA bases. AlkB repair enzymes are the natural defense system against DNA damaging. The AlkB enzyme structure contains an active site iron that in a nonheme conformation is linked to the protein via interactions with $\mathrm{His}_{131}, \mathrm{Asp}_{133}$ and $\mathrm{His}_{187}{ }^{[24]}$ It is also known to use dioxygen and $\alpha \mathrm{KG}$ to hydroxylate methylated DNA bases. As the mechanism was unclear, and the apparent oxygen binding position at a relatively far distance from the substrate methyl group that should be activated, we decided to study its mechanism with quantum mechanics/molecular mechanics (QM/MM) on a complete and solvated enzyme structure. ${ }^{[6,25]}$ In $\mathrm{QM} / \mathrm{MM}$ the complete enzyme plus solvent layer is considered, but only the inner center, the active site, is calculated with quantum chemical methods, while the rest is treated by classical mechanics. ${ }^{[26]}$ These calculations not only take the geometric features of the protein into consideration but also include the long-range electrostatic perturbations of the MM region into the QM Hamiltonian.

We find a novel mechanism as highlighted in Figure 5 for the step starting with the iron(IV)-oxo species $\left({ }^{5} \mathbf{R}\right)$, which is in a quintet spin ground state. Thus, molecular oxygen is expected to approach iron from the top and bind trans to $\mathrm{His}_{131}$. Attempts to bind $\mathrm{O}_{2}$ in alternative positions closer to the substrate failed and we did not manage to converge these geometries. Based on the $\mathrm{QM} / \mathrm{MM}$ results the catalytic cycle of AlkB repair enzymes includes an additional step with respect to Figure 2, whereby the iron(IV)-oxo rotates from trans to $\mathrm{His}_{131}$ to trans to $\mathrm{His}_{187}$, see Figure 5. This isomerization has a barrier of $9.0 \mathrm{kcal} \mathrm{mol}^{-1}$ (via ${ }^{5} \mathbf{T S}_{\text {iso }}$ ) and leads to the rotated iron(IV)-oxo species ( $\left({ }^{5}\right.$ '). The rotation and isomerization is gated by an active site Arg residue $\left(\operatorname{Arg}_{210}\right)$ that is in hydrogen bonding distance with the oxo group and moves position during the rotation.

In the rotated form, i.e. ${ }^{5} \mathbf{R}$ ', the oxo group is close to the methyl group of methylated adenine and will pick up a hydrogen atom to form an iron(III)-hydroxo species via a hydrogen atom abstraction barrier $\left({ }^{5} \mathbf{T S}_{\mathrm{H}}\right)$. Finally, an $\mathrm{OH}$ rebound gives the alcohol product complex $\left({ }^{5} \mathbf{P}\right)$. The hydrogen atom abstraction is rate determining and as it happens we located two different electromers at 12.2 and $12.6 \mathrm{kcal} \mathrm{mol}^{-1}$ above ${ }^{5} \mathbf{R}$ in energy, namely ${ }^{5} \mathbf{T} \mathbf{S}_{\mathrm{H}, \sigma}$ and ${ }^{5} \mathbf{T} \mathbf{S}_{\mathrm{H}, \pi}$. These two transition states connect to two close-lying iron(III)-hydroxo intermediates with different electronic configuration labeled ${ }^{5} \mathbf{I}_{\mathrm{H}, \sigma}$ and ${ }^{5} \mathbf{I}_{\mathrm{H}, \pi}$. The final radical rebound from both intermediates gives the same product complex ${ }^{5} \mathbf{P}$ 


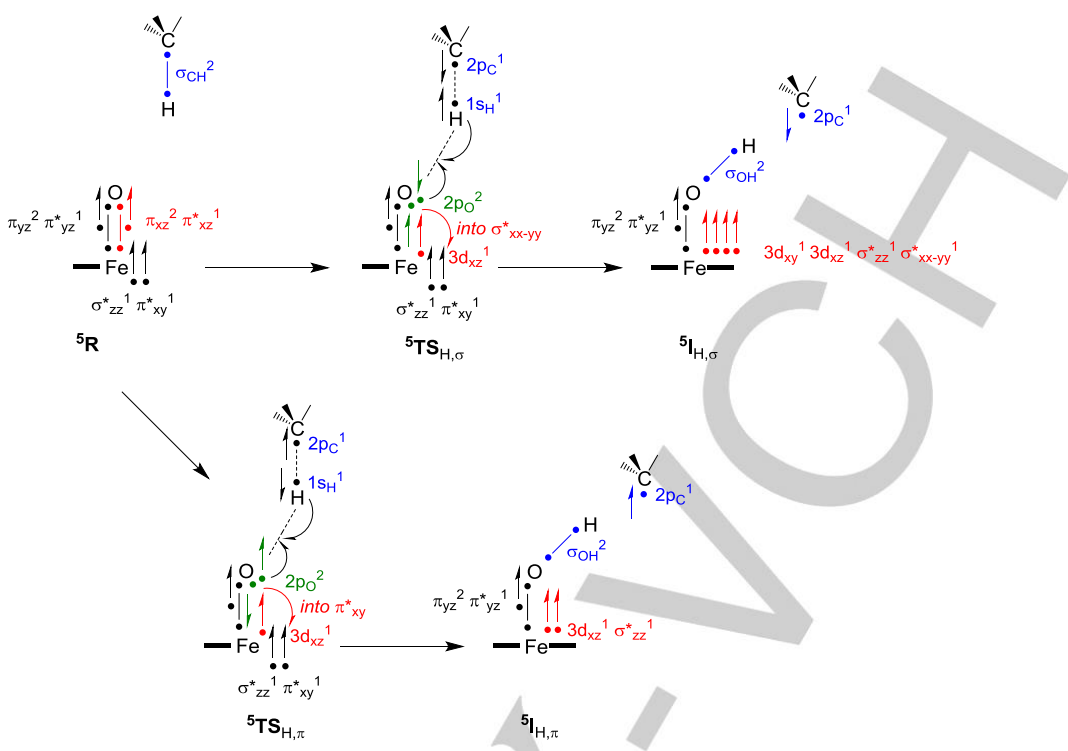

Figure 6. Electron transfer pathways for hydrogen atom abstraction via the ${ }^{5} \sigma$ and ${ }^{5} \pi$-pathways. Electrons are represented by a dot and a line between the dots is a chemical bond occupied by two electrons.

Nonheme iron reactivities often display these $\sigma$ - and $\pi$-pathways during substrate activation. ${ }^{[27]}$ To understand the difference in electronic configuration of the pair of structures ${ }^{5} \mathbf{T S}_{\mathrm{H}, \sigma} /^{5} \mathbf{I}_{\mathrm{H}, \sigma}$ on the one hand and ${ }^{5} \mathbf{T S}_{\mathrm{H}, \pi}{ }^{5} \mathbf{I}_{\mathrm{H}, \pi}$ on the other hand, we show in Figure 6 a valence bond diagram that gives the electron distribution for each of the structures and the electron transfer and bond breaking/forming processes during the reaction. These types of diagrams we used previously to explain the origin of bifurcation processes in chemical catalysis ${ }^{[28]}$ and to rationalize trends and substrate activation reactions. ${ }^{[29]}$

In short, the valence bond diagram displays electrons as a do and a chemical bond occupied by two electrons as a line with two dots. In the reactant state $\left({ }^{5} \mathbf{R}\right)$, the iron(IV)-oxo is in the quintet spin state with molecular occupation $\pi_{\mathrm{xz}}{ }^{2} \pi^{*}{ }_{\mathrm{xz}}{ }^{1} \pi_{\mathrm{yz}}{ }^{2} \pi_{\mathrm{yz}}^{*}$ $\pi^{*}{ }^{1}{ }^{1} \quad \sigma^{*}{ }_{z 2}^{1}$. The $\pi_{x z} / \pi^{*}{ }_{x z}$ and $\pi_{y z} / \pi^{*} y z$ couples represent the antibonding interactions of the metal and oxo groups along the $\mathrm{Fe}-\mathrm{O}$ bond in the $\mathrm{xz}$ and $\mathrm{yz}$ planes, respectively. These two pairs of orbitals correspond to two three-electron bonds and in addition to those two unpaired electrons there are two more in $\pi^{*}$ xy (in the xy-plane with His ${ }_{187}, A_{s p_{133}}$ and succinate) and the $\sigma^{*}{ }_{z 2}$ orbital (along the $\mathrm{Fe}-\mathrm{O}$ axis). Finally there are two electrons in the $\mathrm{C}-\mathrm{H}$ bond of the substrate in the $\sigma_{\mathrm{CH}}$ orbital. Upon homolytic cleavage of $\mathrm{C}-\mathrm{H}$ bond of the substrate, the $\sigma_{\mathrm{CH}}$ molecular orbital splits back into two atomic orbitals $\left(2 \mathrm{p}_{\mathrm{c}}\right.$ and $1 \mathrm{~s}_{\mathrm{H}}$ ) with one electron each. The electron in the $1 \mathrm{~s}_{\mathrm{H}}$ orbital pairs up with an electron on the oxo group (in $2 \mathrm{p}_{\mathrm{o}}$ ) and forms a new $\sigma_{\mathrm{OH}}$ orbital in the iron(III)-hydroxo intermediate. The $2 \mathrm{p}_{\mathrm{o}}$ electron comes from reverting the $\pi_{x z} / \pi^{*}{ }_{x z}$ three-electron bond to atomic orbitals that transfers two electrons to iron and leaves oxygen with one.
Technically, homolytic cleavage of the $\sigma_{\mathrm{CH}}$ bond can give an upspin in $2 p_{C}$ and a down-spin in $1 \mathrm{~s}_{\mathrm{H}}$ or vice versa. In the case the $2 p_{c}$ electron is up-spin, the total spin on the metal-hydroxo fragment will add up to quartet spin to keep the overall quintet spin state. As a result, the two electrons originating from the $\pi_{x z} / \pi^{*} \times z$ orbitals that transfer to iron will have opposite spins and transfer to $3 d_{x z}$ (as up-spin) and $\pi_{x y}^{*}$ (as down-spin). Due to the latter electron transfer this pathway is called the ${ }^{5} \pi$-pathway.

In the alternative pathway $\left({ }^{5} \sigma\right.$-pathway, top of Figure 6$)$, the breaking of the $\pi_{x z} / \pi^{*}{ }_{x z}$ orbital leads to splitting into $2 p_{0}$ (downspin), $3 d_{x z}$ (up-spin) and $\sigma^{*}{ }_{x 2-y 2}$ (up-spin). This pathway will have the substrate radical with a down-spin electron and the metal with five unpaired electrons in $3 d_{x z}, \pi^{*}{ }_{x y}, \pi^{*}{ }_{y z}, \sigma_{z 2}^{*}$ and $\sigma^{*}{ }_{x 2-y 2}$. Usually in nonheme iron(IV)-oxo species the ${ }^{5} \sigma$-pathway is well lower in energy than the ${ }^{5} \pi$-pathway. ${ }^{[30]}$ However, due to the rotation and the change in orbital energy levels in ${ }^{5} R$ ' the two pathways become competitive and both are accessible for AlkB. Nevertheless, both pathways lead to the same final product and it will not have an effect on product distributions.

\subsection{Stereoselectivity of prolyl-4-hydroxylase}

Prolyl-4-hydroxylase ( $\mathrm{P} 4 \mathrm{H})$ is an important nonheme iron dioxygenase with relevance for human health that catalyzes the regio- and stereospecific hydroxylation of proline residues in a peptide chain to R-4-hydroxyproline (Scheme 2). ${ }^{[8,31]}$ Thus, R-4hydroxyproline is an very common amino acid in collagen and is involved in the crosslinking and stabilization of its triple helix structure. As such understanding the mechanism of substrate activation by $\mathrm{P} 4 \mathrm{H}$ is relevant to aging processes in the body and has received considerable attention. 


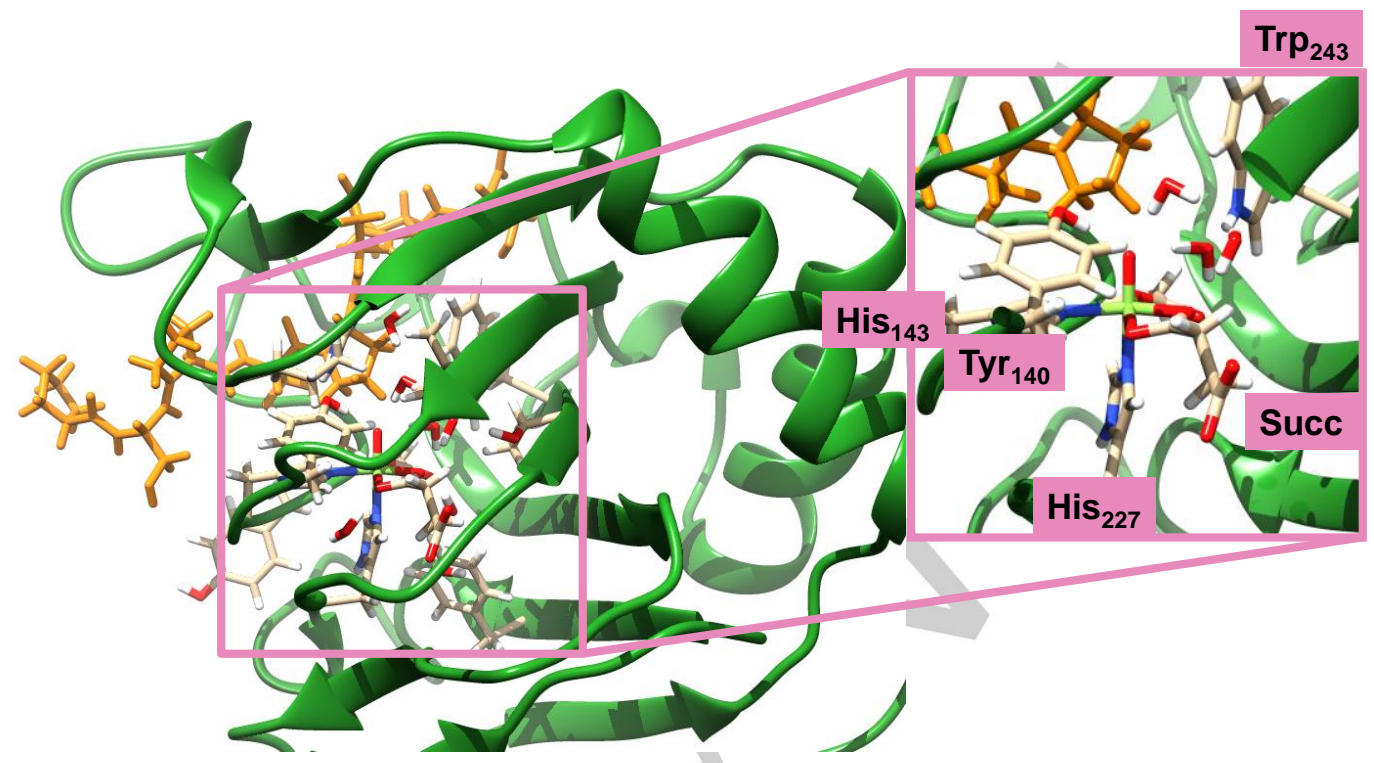

Figure 7. QM/MM optimized geometry of the iron(IV)-oxo species of wildtype $\mathrm{P} 4 \mathrm{H}$ enzymes. The protein substrate is in orange and the enzyme backbone in green, Succ stands for succinate.

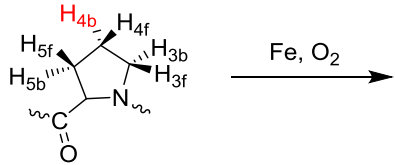

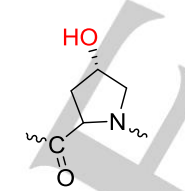

$R$-4-hydroxyproline

Scheme 2. Reaction catalyzed by P4H enzymes.

Our initial studies on this protein used an active site mode complex that only contained the first coordination sphere amino acids of the iron and substrate and lacked the full protein environment. The reaction pathways of proline hydroxylation at the $\mathrm{C}_{3}, \mathrm{C}_{4}$ and $\mathrm{C}_{5}$ positions by an iron(IV)-oxo reactant were investigated with density functional theory methods. ${ }^{[32]}$ It was found that thermochemically the favorable pathway is $\mathrm{C}_{5}$ hydroxylation in contrast to what is observed in $\mathrm{P} 4 \mathrm{H}$ in Nature. This is not surprising as generally hydrogen atom abstraction barriers by metal-oxo oxidants correlate linearly with the strength of the $\mathrm{C}-\mathrm{H}$ bond of the substrate that is broken. ${ }^{[33]}$ Consequently, the most favorable process in the gas-phase should always correspond to activation of the weakest $\mathrm{C}-\mathrm{H}$ bond of the substrate. As the $\mathrm{C}_{4}-\mathrm{H}$ bond dissociation energy is larger than the $\mathrm{C}_{5}-\mathrm{H}$ bond dissociation energy in proline, based on the relative bond strength the most favorable product should be 5 hydroxyproline as observed with the gas-phase model.

We expected the origin of this selectivity to have to do with the protein environment. Thus, increasing the model size with aromatic active site residues, such as $\mathrm{Tyr}_{140}$ and $\operatorname{Trp}_{243}$, changed the regioselectivity in favor of $\mathrm{C}_{4}$-hydroxylation. ${ }^{[32]}$

More recently, we did a detailed QM/MM study on $\mathrm{P} 4 \mathrm{H}$ and focused on the substrate hydroxylation of all six hydrogen atoms at the $\mathrm{C}_{3}, \mathrm{C}_{4}$ and $\mathrm{C}_{5}$ positions (back and front) of wildtype and mutant structures and explored the effect of the protein environment on the selectivity and activity. ${ }^{[34]}$ Our QM/MM study considered a large QM region that included the iron with first coordination sphere groups, the proline residue from the protein chain, the active site $\operatorname{Tyr}_{140}$ and $\operatorname{Trp}_{243}$ side chains and three water molecules. Figure 7 shows the optimized geometry of the iron(IV)-oxo species of wildtype, which is in a quintet spin ground state. The substrate approaches the iron(IV)-oxo species in a cleft lined up by the $\mathrm{Tyr}_{140}$ and $\operatorname{Trp}_{243}$ residues. Furthermore, the oxo group forms hydrogen bonding interactions with the phenol group of $\operatorname{Tyr}_{140}$ and via a bridging water molecule also to $\operatorname{Trp}_{243}$. Hence, the oxo group is in a very rigid position and locked in a specific orientation through a strong hydrogen bonding network of interactions.

Subsequently, the hydrogen atom abstraction reaction was calculated with $\mathrm{QM} / \mathrm{MM}$, whereby each of the aliphatic hydrogen atoms on $\mathrm{C}_{3}, \mathrm{C}_{4}$ and $\mathrm{C}_{5}$ (back as well as front) were activated, see Table 1 for details. As the substrate is located in a very rigid orientation and oxidant approach is hampered by bulky aromatic residues, e.g. $\operatorname{Tyr}_{140}$ and $\operatorname{Trp}_{243}$, but also through hydrogen bonding interactions, we find a large variety of hydrogen atom abstraction barriers for these hydrogen atom abstraction positions. Thus, despite the fact that the bond dissociation energies for all six $\mathrm{C}-\mathrm{H}$ bonds of proline are within $10 \mathrm{kcal} \mathrm{mol}^{-1}$, the range in hydrogen atom abstraction barriers is well larger than that. In particular, for wildtype only three hydrogen atom abstraction barriers are below $30 \mathrm{kcal} \mathrm{mol}^{-1}$, namely from $\mathrm{H}_{4 \mathrm{~b}}$, 
$\mathrm{H}_{4 \mathrm{f}}$ and $\mathrm{H}_{5 \mathrm{~b}}$. The other three aliphatic hydrogen atoms $\left(\mathrm{H}_{5 f}, \mathrm{H}_{3 \mathrm{~b}}\right.$ and $\mathrm{H}_{3 f}$ ) are selectively blocked through positioning of the substrate and substrate approach. Thus, substrate binding and orientation is critical in $\mathrm{P} 4 \mathrm{H}$ enzymes and guides the proline residue into the proper configuration, so that the preferred hydrogen atom in abstracted. Indeed, the lowest energy hydrogen atom abstraction barrier found from the QM/MM calculations is the pathway leading to R-4-hydroxyproline, which is the experimentally observed and expected product. Therefore, the $\mathrm{QM} / \mathrm{MM}$ calculations predict the correct regio- and stereoselectivity for the reaction.

Table 1. QM/MM calculated hydrogen atom abstraction barriers from various $\mathrm{C}-\mathrm{H}$ bonds of proline by $\mathrm{P} 4 \mathrm{H}$ and mutants ${ }^{[\mathrm{a}]}$

\begin{tabular}{lcccc}
\hline Variant & $\Delta \mathrm{E}_{\mathrm{C} 4 \mathrm{~b}}^{\ddagger}$ & $\Delta \mathrm{E}_{\mathrm{C} 4 \mathrm{f}}$ & $\Delta \mathrm{E}_{\mathrm{C} 5 \mathrm{~b}}^{\ddagger}$ & others $^{[\mathrm{b}]}$ \\
\hline WT & 20.7 & 21.7 & 26.2 & $>30$ \\
Y140F & 57.3 & 56.3 & 39.2 & $>30$ \\
Y140G & 19.0 & 16.4 & 43.5 & $>30$ \\
W243F & 21.8 & 26.4 & 18.4 & $>30$ \\
W243G & 35.5 & 75.9 & 41.8 & $>30$ \\
R161D & 60.4 & 60.8 & 45.4 & $>30$ \\
R161Q & 46.1 & 48.3 & $>30$ & $>30$ \\
E127D & 11.6 & 20.8 & 12.5 & $>30$ \\
E127Q & 25.0 & $>30$ & 20.1 & $>30$
\end{tabular}

[a] Energies in $\mathrm{kcal}^{\mathrm{mol}}{ }^{-1}$. [b] barriers for hydrogen atom abstraction from $\mathrm{H}_{5 \mathrm{f}}$, $\mathrm{H}_{3 b}$ and $\mathrm{H}_{3 f}$

The combined density functional theory and QM/MM calculations on $\mathrm{P} 4 \mathrm{H}$ enzyme activity show that the regioselectivity of proline hydroxylation does not follow the thermodynamically most favorable pathway as that should lead to 5-hydroxyproline products instead. ${ }^{[32,34]}$ Therefore, the shape and size of the substrate binding pocket and the approach of the oxidant by substrate must determine the selectivity and enable a regioselective activation of the unfavorable $\mathrm{C}_{4}$ position efficiently.

To understand the importance of specific amino acid residues in $\mathrm{P} 4 \mathrm{H}$ enzymes better, we made single mutants, whereby either the $\operatorname{Tyr}_{140}, \operatorname{Trp}_{243}, \operatorname{Arg}_{161}$ or $\mathrm{Glu}_{127}$ amino acids were replaced by other residues. Figure 8 displays the active site structure of $\mathrm{P} 4 \mathrm{H}$ and highlights the position of these individual residues. As mentioned above, $\mathrm{Tyr}_{140}$ is in hydrogen bonding distance to the iron(IV)-oxo group (in purple in Figure 8 ) and has its aromatic residue parallel to $\mathrm{His}_{143}$. Substrate approaches the iron(IV)-oxo species in a cleft shielded by $\operatorname{Tyr}_{140}, \operatorname{Trp}_{243}$ and $\mathrm{Asp}_{145}$ with the $\mathrm{C}_{4}$ position of the substrate pointing towards the oxo group. The substrate protein chain (Ser-Pro $)_{5}$ bends around the $\operatorname{Trp}_{243}$ residue and is held in position by hydrogen bonding interactions of the side chains of $\operatorname{Arg}_{161}$ (parallel to $\operatorname{Trp}_{243}$ ) and $\mathrm{Glu}_{127}$.

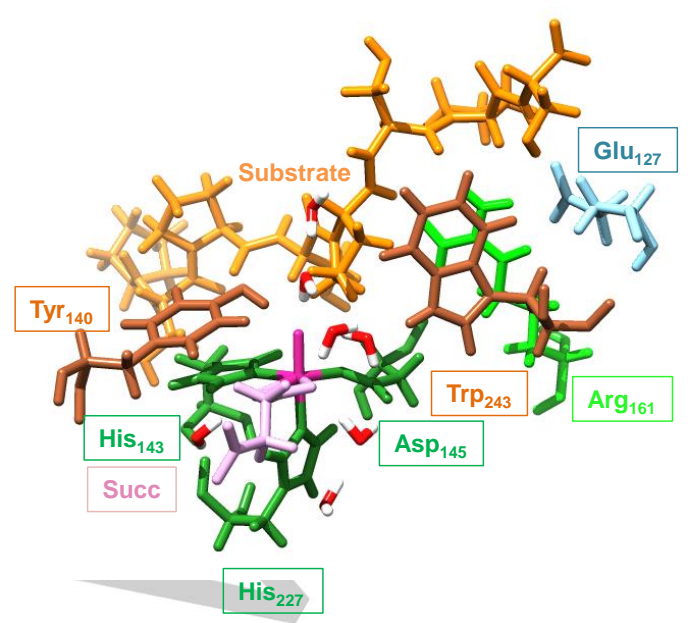

Figure 8. $\mathrm{P} 4 \mathrm{H}$ active site structure as calculated with $\mathrm{QM} / \mathrm{MM}$ and the position of amino acid residues with respect to substrate.

Mutants were manually created computationally by replacing the aromatic residues $\operatorname{Tyr}_{140} / \operatorname{Trp}_{243}$ with either Phe or Gly, while the polar residues $\mathrm{Glu}_{127} / \mathrm{Arg}_{161}$ were substituted by Asp or Gln. After the mutants were created, the proteins were solvated and a molecular dynamics (MD) simulation run. From the MD simulation starting points for the QM/MM calculations were taken and the hydrogen atom abstraction of all six positions of proline were calculated again (Table 1). As can be seen from the summary in Table 1, these single mutants give a dramatic shift in substrate activation, selectivity and activity with respect to wildtype enzyme. Thus replacing $\mathrm{Tyr}_{140}$ by a Phe group leads to the loss of the hydrogen bond with the oxo group and raises the hydrogen atom abstraction barriers dramatically. This effect is not as dramatic as replacing $\operatorname{Tyr}_{140}$ by Gly as it fills the pocket with water molecules that take over its role. However, in the Tyr140Gly mutant the substrate has more flexibility and hydrogen atom abstraction of $\mathrm{H}_{4 \mathrm{f}}$ becomes the lowest energy hydrogen atom abstraction barrier. Therefore, the Tyr140Gly mutant gives loss of selectivity, while the Tyr140Phe mutant shows complete loss of activity. For the Trp243Phe mutant also loss of selectivity is seen, whereby the lowest hydrogen atom abstraction barrier is found for $\mathrm{H}_{5 b}$.

Apart from the active site $\mathrm{Tyr}_{140}$ and $\operatorname{Trp}_{243}$ residues, we also investigated mutants of the $\mathrm{Glu}_{127}$ and $\mathrm{Arg}_{161}$ residues. These two amino acids are located in a substrate loop and hold it in tight conformation. Both Arg mutants become inactive and hence $\operatorname{Arg}_{161}$ is essential for substrate positioning in the active site. Only a minor change in hydrogen atom abstraction barriers is seen when $\mathrm{Glu}_{127}$ is replaced by Asp, but a mutation into GIn makes $\mathrm{H}^{5 \mathrm{~b}}$ the most likely hydrogen atom abstraction position. Therefore, minor changes to the protein through single mutation can lead to inactivity of $\mathrm{P} 4 \mathrm{H}$ enzymes or regioselectivity switches. As such the substrate binding position is tightly controlled by the protein environment. 
(a)

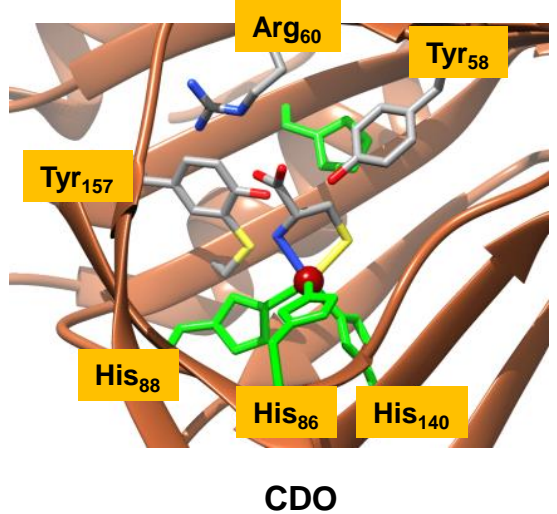

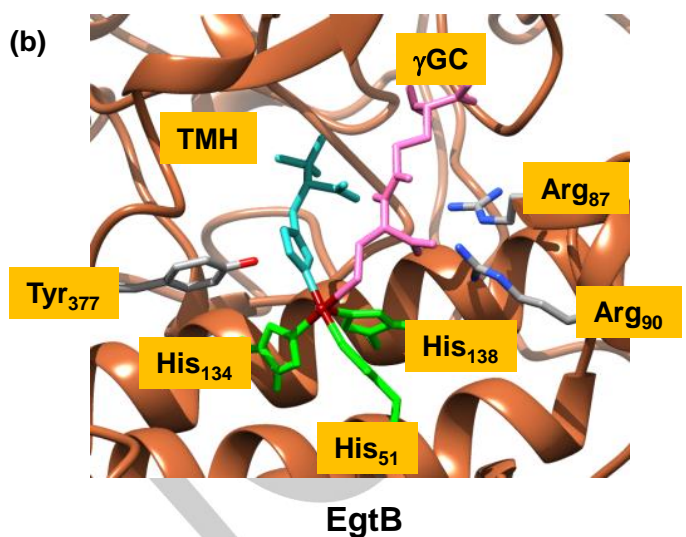

Figure 9. Substrate bound active site structures of $\mathrm{CDO}$ (left) and EgtB (right) as taken from the 4IEV and 4X8D pdb files. TMH stands for $\mathrm{N}-\alpha$-trimethyl histidine and $\gamma \mathrm{GC}$ for $\gamma$-glutamyl cysteine.

\subsection{Ergothioneine Biosynthesis enzyme}

There are several nonheme iron dioxygenases in nature that bind and activate sulfur-containing substrates, such as cysteine residues. These cysteine-activating nonheme iron dioxygenases often bind the iron to the protein via a 3 -His rather than the 2 His/1-Asp coordination scheme. ${ }^{[9,35]}$ Thus, cysteine dioxygenase (CDO) bind cysteine to an iron center through the amide and thiolate groups and links to the protein through a 3-His linkage, Figure $9 .{ }^{[36]}$ It has a tight substrate binding pocket where the amide and carboxylate groups of cysteine interact with polar side chains of active site residues $\mathrm{Tyr}_{58}, \operatorname{Arg}_{60}$, and $\mathrm{Tyr}_{157}$. We studied the mechanism for the conversion of cysteine into cysteine sulfinic acid with a range of computational techniques, including density functional theory calculations on model complexes as well as $\mathrm{QM} / \mathrm{MM}^{[37]}$ The general reaction mechanism for CDO involves cysteine and dioxygen binding followed by the attack of the terminal oxygen atom on sulfur to form a bicyclic ring structure similar to structure $\mathbf{D}$ in Figure 2 above. Then $\mathrm{O}-\mathrm{O}$ bond cleavage gives an iron(IV)-oxo species and cysteine sulfoxide and forms final products cysteine sulfinic acid through a second oxygen atom transfer reaction.

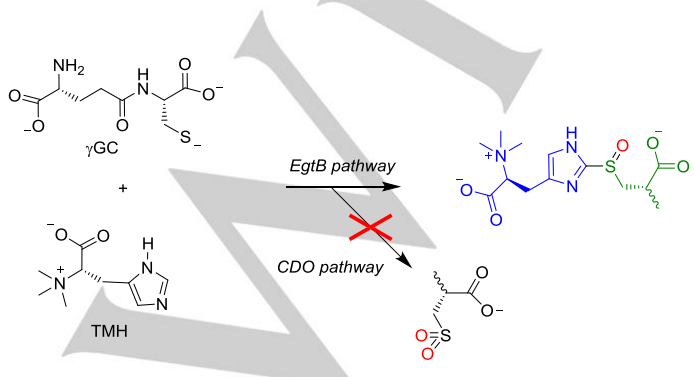

Scheme 3. Reaction catalyzed by EgtB enzymes.
Using computational modelling it was shown that replacing one of the His ligands of CDO by Asp changes the individual barriers of the reaction mechanism and affects the kinetics. ${ }^{[37 b]}$ In particular, substrate cysteinate is found to bind weaker when a carboxylate ligand is ligated to the iron in the same coordination plane and hence the cysteine dioxygenation process is more efficient when iron is ligated to neutral His groups only.

Another nonheme iron dioxygenase that binds a cysteinatebased substrate is the ergothioneine biosynthesis enzyme (EgtB) and its substrates bound structure is shown on the righthand-side of Figure 9. EgtB binds $\mathrm{N}$ - $\alpha$-trimethyl histidine $(\mathrm{TMH})$ and $\gamma$-glutamyl cysteine $(\gamma \mathrm{GC})$ as substrates directly to the iron and links them together by forming a $\mathrm{C}-\mathrm{S}$ bond and in addition performs a sulfoxidation, i.e. EgtB is a sulfoxide synthase (Scheme 3). Its active site shows similarities to CDO, where the metal is bound to three histidine residues ( $\mathrm{His}_{51}, \mathrm{His}_{134}, \mathrm{His}_{138}$ ), but also has polar active site residues such as $\mathrm{Tyr}_{377}, \operatorname{Arg}_{87}$ and $\mathrm{Arg}_{90}$ with unknown function. Interestingly, although EgtB utilizes $\mathrm{O}_{2}$ on an iron center that binds a cysteinate residue, the wildtype structure is not known to perform cysteine dioxygenase reactivity. To find out how the protein avoids cysteine dioxygenation in EgtB enzymes and catalyzes a sulfoxide synthase reaction instead, a QM/MM study was performed. ${ }^{\left[{ }^{[3]}\right.}$

Figure 10 shows the $Q M / M M$ calculated reaction mechanism for substrate activation by EgtB enzymes starting from the quintet spin iron(III)-superoxo reactant structure $\left({ }^{5} \mathbf{R e}\right)$. The lowest energy mechanism is initiated by proton transfer from a nearby Tyr residue to the superoxo group (via ${ }^{5} \mathbf{T S}_{\mathrm{PT}}$ ) to form the iron(III)-hydroperoxo $\left({ }^{5} \mathbf{I}_{1}\right)$ species in an almost thermoneutral step. This intermediate is inactive but withdraws electron density from the sulfur and makes it more radical-type, so that it is able to attack the $C^{2}$ position of the imidazole ring of $\mathrm{TMH}$ (via transition state ${ }^{5} \mathbf{T} \mathbf{S}_{\mathrm{cs}}$ ) to link the two substrates together via a covalent C-S bond $\left({ }^{5} \mathbf{I}_{2}\right)$. The $\mathrm{C}-\mathrm{S}$ bond formation, however, weakens the $\mathrm{Fe}-\mathrm{S}$ bond and polarizes charge density back to iron, which makes the iron(III)-superoxo less acidic. 


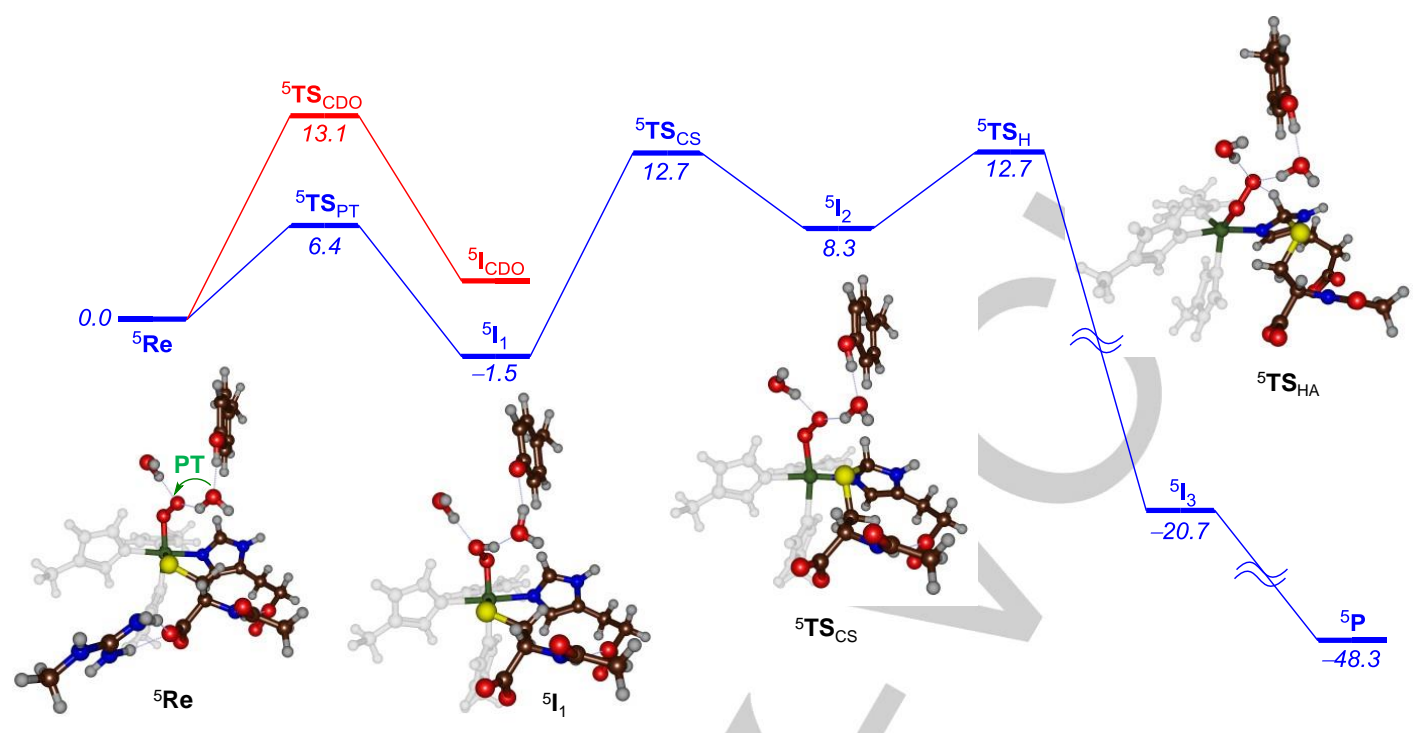

Figure 10. QM/MM calculated reaction mechanisms of sulfoxide synthase versus cysteine dioxygenase pathways in EgtB. Data taken from Ref ${ }^{[38]}$

This triggers a simultaneous proton transfer from iron(III)hydroperoxo back to $\mathrm{Tyr}_{377}$ that leaves an iron(II)-superoxo structure. The $\mathrm{C}-\mathrm{S}$ bond formation between the imidazole group of $\mathrm{TMH}$ and the cysteinate of $\gamma \mathrm{GC}$ has lifted the aromaticity in the imidazole ring and changed the hybridization of $\mathrm{C}^{2}$ from $\mathrm{sp}^{2}$ to $\mathrm{sp}^{3}$. Therefore, the $\mathrm{C}^{2}-\mathrm{H}$ bond in ${ }^{5} \mathrm{I}_{2}$ is reduced from an aromatic to an aliphatic bond, and hence has considerably weakened. This ipso-hydrogen atom can then be abstracted by the iron(II)-superoxo species, so that the imidazole ring relaxes back to aromaticity $\left({ }^{5} \mathbf{I}_{3}\right)$ and gains a large amount of exothermicity. Finally, the iron(II)-hydroperoxo complex reacts with oxygen atom transfer to complete the sulfoxide synthase mechanism to form products.

As such, computation suggests a mechanism for sulfoxide synthase in EgtB that starts with the formation of the C-S bond by inactivation of dioxygen through a nearby tyrosine residue and weakening of the Fe-S bond. Only after the $\mathrm{C}-\mathrm{S}$ bond is completed and the histidine group of TMH back in its aromatic form (through proton release), the sulfoxidation happens. Several alternative reaction mechanisms were tested but were found well higher in energy. In particular, the alternative pathway for oxygen atom transfer from iron(III)-superoxo reactants, similar to the one in CDO, was also tested but a barrier (via ${ }^{5} \mathbf{T S}_{\mathrm{CDO}}$ ) of $13.1 \mathrm{kcal} \mathrm{mol}^{-1}$ was found. Hence, the initial proton transfer step to $\mathrm{Tyr}_{377}$ by-passes the otherwise favorable oxygen atom transfer from iron(III)-superoxo. Therefore, Tyr377 may have an essential function in EgtB to guide the reaction mechanism to the sulfoxide synthase pathway, by temporarily inactivating molecular oxygen through protonation that then weakens the $\mathrm{Fe}-\mathrm{S}$ bond and triggers the $\mathrm{C}-\mathrm{S}$ bond formation. Indeed, mutation of the active site $\mathrm{Tyr}_{377}$ residue led to CDOtype activity in EgtB in agreement with our proposed mechanism. ${ }^{[39]}$

\section{Conclusion}

Nonheme iron dioxygenases show large versatility in substrate activation and in many cases natural systems produce products regioselectively or stereospecifically. Understanding the nature of the protein, and particularly the second coordination sphere effects, requires either large computational model structures or $\mathrm{QM} / \mathrm{MM}$ on the full enzyme. The models and methods used in computational modelling are able to reproduce experimental observations and give detailed insight into short-lived reactive intermediates of enzymes. Furthermore, in several cases our modelling led to predictions that encouraged experimentalists for future studies. For instance in the S-p-hydroxymandelate synthase example given here, the modelling predicted how mutants would give different product distributions. Indeed when these mutants were made a complete eneantioselectivity reversal in the product distributions were obtained. Consequently, computational modelling adds valuable insight alongside experimental studies.

\section{Acknowledgements}

I am grateful for all the $\mathrm{PhD}$ and Master students in my group who did the core of the calculations. Without their hard work and dedication, the work would not have been possible. I also acknowledge Santiago Alvarez (University of Barcelona) for the photo on page 1 and Tamar de Visser for help with the Frontipiece. 
Keywords: density functional theory $\cdot \mathrm{QM} / \mathrm{MM} \cdot$ enzyme mechanism •nonheme iron $\bullet$ enzyme catalysis

11] a) M. Sono, M. P. Roach, E. D. Coulter, J. H. Dawson, Chem Rev. 1996, 96, 2841-2888; b) Cytochrome P450: Structure, Mechanism and Biochemistry (Ed.: P. R. Ortiz de Montellano), $3^{\text {rd }}$ ed., Kluwer Academic/Plenum Publishers, New York, 2005; c) Handbook of Porphyrin Science (Eds.: K. M. Kadish, K. M. Smith, R. Guilard), World Scientific Publishing Co., New Jersey, 2010; d) Iron-containing enzymes: Versatile catalysts of hydroxylation reaction in nature (Eds.: S. P. de Visser, D. Kumar), RSC Publishing, Cambridge (UK), 2011; e) P. R. Ortiz de Montellano, Chem. Rev. 2010, 110, 932-948.

[2] a) E. I. Solomon, T. C. Brunold, M. I. Davis, J. N. Kemsley, S.-K. Lee, N. Lehnert, F. Neese, A. J. Skulan, Y.-S. Yang, J. Zhou, Chem. Rev. 2000 100, 235-349; b) T. D. H. Bugg, Curr. Opin. Chem. Biol. 2001, 5, 550555; c) M. J. Ryle, R. P. Hausinger, Curr. Opin. Chem. Biol. 2002, 6, 193-201; d) M. Costas, M. P. Mehn, M. P. Jensen, L. Que Jr, Chem. Rev. 2004, 104, 939-986; e) M. M. Abu-Omar, A. Loaiza, N. Hontzeas, Chem. Rev. 2005, 105, 2227-2252; f) C. Krebs, D. G. Fujimori, C. T. Walsh, J. M. Bollinger Jr, Acc. Chem. Res. 2007, 40, 484-492; g) P. C. A. Bruijnincx, G. van Koten, R. J. M. Klein Gebbink, Chem. Soc. Rev. 2008, 37, 2716-2744; h) M. Costas, Coord. Chem. Rev. 2011, 255, 2912-2932; i) A. R. McDonald, L. Que Jr, Coord. Chem. Rev. 2013 257, 414-428; j) W. Nam, Y.-M. Lee, S. Fukuzumi, Acc. Chem. Res. 2014, 47, 1146-1154.

[3] a) B. Meunier, S. P. de Visser, S. Shaik, Chem. Rev. 2004, 104, 39473980; b) I. G. Denisov, T. M. Makris, S. G. Sligar, I. Schlichting, Chem. Rev. 2005, 105, 2253-2277; c) J. Rittle, M. T. Green, Science 2010, 330, 933-937; d) T. L. Poulos, Chem. Rev. 2014, 114, 3919-3962.

[4] a) M. Zederbauer, P. G. Furtmüller, S. Brogioni, C. Jakopitsch, G. Smulevich, C. Obinger, Nat. Prod. Rep. 2007, 24, 571-584; b) H.-P. Hersleth, T. Uchida, A. K. Røhr, T. Teschner, V. Schünemann, T. Kitagawa, A. X. Trautwein, C. H. Görbitz, K. K. Andersson, J. Biol. Chem. 2007, 282, 23372-23386; c) B. R. Streit, B. Blanc, G. S. LukatRodgers, K. R. Rodgers, J. L. DuBois, J. Am. Chem. Soc. 2010, 132, 5711-5724; d) A. Gumiero, C. L. Metcalfe, A. R. Pearson, E. L. Raven, P. C. E. Moody, J. Biol. Chem. 2011, 286, 1260-1268.

[5] a) P. Nicholls, I. Fita, P. C. Loewen, Adv. Inorg. Chem. 2001, 51, 51106; b) J. Colin, B. Wiseman, J. Switala, P. C. Loewen, A. Ivancich, J. Am. Chem. Soc. 2009, 131, 8557-8563.

[6] a) H. M. Senn, W. Thiel, Top. Curr. Chem. 2007, 268, 173-290; b) B. Kirchner, F. Wennmohs, S. Ye, F. Neese, Curr. Opin. Chem. Biol. 2007 11, 134-141; c) M. J. Ramos, P. A. Fernandes, Acc. Chem. Res. 2008 41, 689-698; d) M. W. van der Kamp, A. J. Mulholland, Biochemistry 2013, 52, 2708-2728; e) S. P. de Visser, M. G. Quesne, B. Martin, P. Comba, U. Ryde, Chem. Commun. 2014, 50, 262-282; f) S. P. de Visser, M. J. Stillman, Int. J. Mol. Sci. 2016, 17, 519-544.

[7] See, e.g., a) S. Shaik, D. Kumar, S. P. de Visser, A. Altun, W. Thiel, Chem. Rev. 2005, 105, 2279-2328; b) A. Hernández-Ortega, M. G. Quesne, S. Bui, D. J. Heyes, R. A. Steiner, N. S. Scrutton, S. P. de Visser, J. Am. Chem. Soc. 2015, 137, 7474-7487; c) A. S. Faponle, M. G. Quesne, S. P. de Visser, Chem. Eur. J. 2016, 22, 5478-5483.

[8] a) C. J. Schofield, Z. Zhang, Curr. Opin. Struc. Biol. 1999, 9, 722-731; b) A. D. Winter, A. P. Page, Mol. Cell Biol. 2000, 20, 4084-4093; c) K. I. Kivirikko, R. Myllyla, T. Pihlajaniemi, FASEB J. 1989, 3, 1609-1617.

[9] a) M. H. Stipanuk, Annu. Rev. Nutr. 2004, 24, 539-577; b) G. D. Straganz, B. Nidetzky, B. ChemBioChem. 2006, 7, 1536-1548; c) D. Buongiorno, G. D. Straganz, Coord. Chem. Rev. 2013, 257, 541-563.

[10] a) R. Chowdhury, A. Hardy, C. J Schofield, Chem. Soc. Rev 2008, 37 1308-1319; b) J. M. Simmons, T. A. Müller, R. P. Hausinger, Dalton Trans. 2008, 5132-5142.

[11] H. M. Berman, J. Westbrook, Z. Feng, G. Gilliland, T. N. Bhat, H. Weissig, I. N. Shindyalov, P. E. Bourne, Nucleic Acids Res. 2000, 28 , 235-242.

[12] S. P. de Visser, Coord. Chem. Rev. 2009, 253, 754-768.

[13] J. M. Elkins, M. J. Ryle, I. J. Clifton, J. C. Dunning Hotopp, J. S. Lloyd, N. I. Burzlaff, J. E. Baldwin, R. P. Hausinger, P. L. Roach, Biochemistry 2002, 41, 5185-5192.
[14] a) J. C. Price, E. W. Barr, B. Tirupati, J. M. Bollinger Jr, C. Krebs, Biochemistry 2003, 42, 7497-7508; b) D. A. Proshlyakov, T. F. Henshaw, G. R. Monterosso, M. J. Ryle, R. P. Hausinger, J. Am. Chem Soc. 2004, 126, 1022-1023; c) P. J. Riggs-Gelasco, J. C. Price, R. B. Guyer, J. H. Brehm, E. W. Barr, J. M. Bollinger Jr, C. Krebs, J. Am. Chem. Soc. 2004, 126, 8108-8109.

[15] a) T. Borowski, A. Bassan, P. E. M. Siegbahn, Chem. Eur. J. 2004, 10 1031-1041; b) S. P. de Visser, Chem. Commun. 2007, 171-173; c) A. V. Nemukhin, I. A. Topol, R. E. Cachau, S. K. Burt, Theor. Chem. Acc. 2006, 115, 348-353; d) G. Cicero, C. Carbonera, K. Valegård, J. Hajdu, I. Andersson, G. Ranghino, Int. J. Quant. Chem. 2007, 107, 15141522; e) S. Sinnecker, N. Svensen, E. W. Barr, S. Ye, J. M. Bollinger Jr, F. Neese, C. Krebs, J. Am. Chem. Soc. 2007, 129, 6168-6179; f) H. Chen, W. Lai, J. Yao, S. Shaik, J. Chem. Theory Comput. 2011, 7, 3049-3053; g) E. A. C. Bushnell, G. B. Fortowsky, J. W. Gauld, Inorg. Chem. 2012, 51, 13351-13356; h) A. Wójcik, M. Radoń, T. Borowski, J. Phys. Chem. A 2016, 120, 1261-1274; i) B. K. Mai, Y. Kim, Inorg Chem. 2016, 55, 3844-3852.

[16] a) S. P. de Visser, Angew. Chem. Int. Ed. 2006, 45, 1790-1793; b) S. P. de Visser, J. Am. Chem. Soc. 2006, 128, 9813-9824; c) E. Godfrey, C. S. Porro, S. P. de Visser, J. Phys. Chem. A 2008, 112, 2464-2468; d) R. Latifi, M. Bagherzadeh, S. P. de Visser, Chem. Eur. J. 2009, 15, 6651-6662.

[17] O.W. Choroba, D. H. Williams, J. B. Spencer, J. Am. Chem. Soc. 2000, 122, 5389-5390.

[18] a) Hubbard, B. K.; Thomas, M. G.; Walsh, C. T. Chem. Biol. 2000, 7, 931-942; b) Gunsior, M.; Ravel, J.; Challis, G. L.; Townsend, C. A. Biochemistry 2004, 43, 663-674; c) Neidig, M. L.; Decker, A.; Choroba, O. W.; Huang, F.; Kavana, M.; Moran, G. R.; Spencer, J. B.; Solomon, E. I. Proc. Natl. Acad. Sci. USA 2006, 103, 12966-12973; d) Di Giuro, C. M. L.; Konstantinovics, C.; Rinner, U.; Nowikow, C.; Leitner, E.; Straganz, G. D. Plos One 2013, 8, e68932.

[19] a) A. Wócicik, E. Broclawik, P. E. M. Siegbahn, T. Borowski, Biochemistry 2012, 51, 9570-9580; b) Hirao, H.; Morokuma, K. J. Am. Chem. Soc. 2011, 133, 14550-14553.

[20] D. D. Shah, J. A. Conrad, G. R. Moran, Biochemistry 2013, 52, 60976107

[21] J. Brownlee, P. He, G. R. Moran, D. H. Harrison, Biochemistry 2008, 47, 2002-2013.

[22] S. M. Pratter, C. Konstantinovics, C. L. M. DiGiuro, E. Leitner, D. Kumar, S. P. de Visser, G. Grogan, G. D. Straganz, Angew. Chem. Int. Ed. 2013, 52, 9677-9681.

[23] a) S. C. Trewick, T. F. Henshaw, R. P. Hausinger, T. Lindahl, B. Sedgwick, Nature 2002, 419, 174-178; b) P. Ø. Falnes, R. F. Johansen, E. Seeberg, Nature 2002, 419, 178-182; c) P. J. O'Brien, Chem. Rev. 2006, 106, 720-752; d) C. Yi, C. G. Yang, C. He, Acc. Chem. Res. 2009, 42, 519-529.

[24] B. Yu, W. C. Edstrom, J. Benach, Y. Hamuro, P. C. Weber, B. R. Gibney, J. F. Hunt, Nature 2006, 439, 879-884.

[25] M. G. Quesne, R. Latifi, L. E. Gonzalez-Ovalle, D. Kumar, S. P. de Visser, Chem. Eur. J. 2014, 20, 435-446.

[26] a) J. Gao, D. G. Truhlar, Annu. Rev. Phys. Chem. 2002, 53, 467-505; b) P. Vidossich, A. Magistrato, Biomolecules 2014, 4, 616-645; c) M. W. van der Kamp, A. J. Mulholland, Biochemistry 2013, 52, 2708-2728; d) C. Bo, F. Maseras, Dalton Trans. 2008, 2911-2919; e) E. Rosta, M. Klähn, A. Warshel, J. Phys. Chem. B 2006, 110, 2934-2941; f) M. G. Quesne, T. Borowski, S. P. de Visser, Chem. Eur. J. 2016, 22, $2562-$ 2581.

[27] a) L. Bernasconi, E.-J. Baerends, Eur. J. Inorg. Chem. 2008, 1672 1681 ; b) S. D. Wong, C. B. Bell III, L. V. Liu, Y. Kwak, J. England, E. E. Alp, J. Zhao, L. Que Jr, E. I. Solomon, Angew. Chem. Int. Ed. 2011, 50, 3215-3218; c) S. P. de Visser, J. Am. Chem. Soc. 2006, 128, 1580915818; d) S. Sahu, L. R. Widger, M. G. Quesne, S. P. de Visser, H. Matsumura, P. Moënne-Loccoz, M. A. Siegler, D. P. Goldberg, J. Am. Chem. Soc. 2013, 135, 10590-10593; e) S. Ye, F. Neese, Proc. Natl. Acad. Sci. USA 2011, 108, 1228-1233; f) F. G. Cantú Reinhard, S. P. de Visser, Chem. Eur. J. 2017, 23, 2935-2944.

[28] a) D. Kumar, L. Tahsini, S. P. de Visser, H. Y. Kang, S. J. Kim, W. Nam, J. Phys. Chem. A 2009, 113, 11713-11722; b) L. Ji, A. S. Faponle, M. 
G. Quesne, M. A. Sainna, J. Zhang, A. Franke, D. Kumar, R. van Eldik, W. Liu, S. P. de Visser, Chem. Eur. J. 2015, 21, 9083-9092; c) P. Barman, A. S. Faponle, A. K. Vardhaman, D. Angelone, A.-M. Löhr, W. R. Browne, P. Comba, C. V. Sastri, S. P. de Visser, Inorg. Chem. 2016, 55, 10170-10181

[29] a) D. Kumar, G. N. Sastry, S. P. de Visser, Chem. Eur. J. 2011, 17 6196-6205; b) M. A. Sainna, S. Kumar, D. Kumar, S. Fornarini, M. E. Crestoni, S. P. de Visser, Chem. Sci. 2015, 6, 1516-1529; c) F. G. Cantú Reinhard, M. A. Sainna, P. Upadhyay, G. A. Balan, D. Kumar, S. Fornarini, M. E. Crestoni, S. P. de Visser, Chem. Eur. J. 2016, 22, 18608-18619; d) N. J. Fowler, C. F. Blanford, J. Warwicker, S. P. de Visser, Chem. Eur. J. 2017, 23, 15436-15445.

[30] a) A. K. Vardhaman, P. Barman, S. Kumar, C. V. Sastri, D. Kumar, S. P. de Visser, Angew. Chem. Int. Ed. 2013, 52, 12288-12292; b) S. Kumar, A. S. Faponle, P. Barman, A. K. Vardhaman, C. V. Sastri, D. Kumar, S. P. de Visser, J. Am. Chem. Soc. 2014, 136, 17102-17115.

[31] a) R. K. Bruick, S. L. McKnight, Science 2001, 294, 1337-1340; b) J. D. Vasta, A. Choudhary, K. H. Jensen, N. A. McGrath, R. T. Raines, Biochemistry 2017, 56, 219-227; c) L. M. Hoffart, E. W. Barr, R. B. Guyer, J. M. Bollinger Jr, C. Krebs, Proc. Natl. Acad. Sci. USA 2006 , 103, 14738-14743.

[32] B. Karamzadeh, D. Kumar, G. N. Sastry, S. P. de Visser, J. Phys. Chem. A 2010, 114, 13234-13243.

[33] a) S. Shaik, D. Kumar, S. P. de Visser, J. Am. Chem. Soc. 2008, 130 10128-10140; b) S. P. de Visser, J. Am. Chem. Soc. 2010, 132, 10871097.
[34] a) A. Timmins, M. Saint-André, S. P. de Visser, J. Am. Chem. Soc. 2017, 139, 9855-9866; b) A. Timmins, S. P. de Visser, Frontiers Chem. 2017, 5, Article 94, pp 1-13.

[35] a) J. E. Dominy Jr, C. R. Simmons, L. L. Hirschberger, J. Hwang, R. M. Coloso, M. H. Stipanuk, J. Biol. Chem. 2007, 282, 25189-25198; b) E. P. Tchesnokov, M. Fellner, E. Siakkou, T. Kleffmann, L. W. Martin, S. Aloi, I. L. Lamont, S. M. Wilbanks, G. N. L. Jameson, J. Biol. Chem. 2015, 290, 24424-24437.

[36] a) C. M. Driggers, R. B. Cooley, B. Sankaran, L. L. Hirschberger, M. H. Stipanuk, P. A. Karplus, J. Mol. Biol. 2013, 425, 3121-3136; b) K. V. Goncharenko, A. Vit, W. Blankenfeldt, F. P. Seebeck, Angew. Chem. Int. Ed. 2015, 54, 2821-2824.

[37] a) S. Aluri, S. P. de Visser, J. Am. Chem. Soc. 2007, 129, 1484614847 ; b) S. P. de Visser, G. D. Straganz, J. Phys. Chem. A 2009, 113, 1835-1846; c) D. Kumar, W. Thiel, S. P. de Visser, J. Am. Chem. Soc. 2011, 133, 3869-3882; d) M. Fellner, E. Siakkou, A. S. Faponle, E. P. Tchesnokov, S. P. de Visser, S. M. Wilbanks, G. N. L. Jameson, J. Biol. Inorg. Chem. 2016, 21, 501-510; e) E. P. Tchesnokov, A. S. Faponle, C. G. Davies, M. G. Quesne, R. Turner, M. Fellner, R. J. Souness, S. M. Wilbanks, S. P. de Visser, G. N. L. Jameson, Chem. Commun. 2016, 52, 8814-8817.

[38] A. S. Faponle, F. P. Seebeck, S. P. de Visser, J. Am. Chem. Soc. 2017, 139, 9259-9270.

[39] K. V. Goncharenko, F. P. Seebeck, Chem. Commun. 2016, 52, 19451948 


\section{Entry for the Table of Contents}

Layout 1:

\section{PERSONAL ACCOUNT}

Computational studies are useful tools for the studies of fast reaction mechanisms as they happen inside enzymes. In this personal account I review recent work of our group focused on the understanding of the regio- and stereoselectivity of

enzymatic reaction mechanisms. In one example I also show how theory made successful predictions on how to bioengineer a protein.

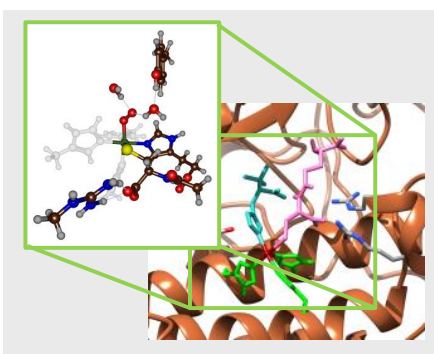

Sam P. de Visser

\section{Page No. - Page No.}

Mechanistic insight on the activity and substrate selectivity of nonheme iron dioxygenases 


\section{Frontipiece:}

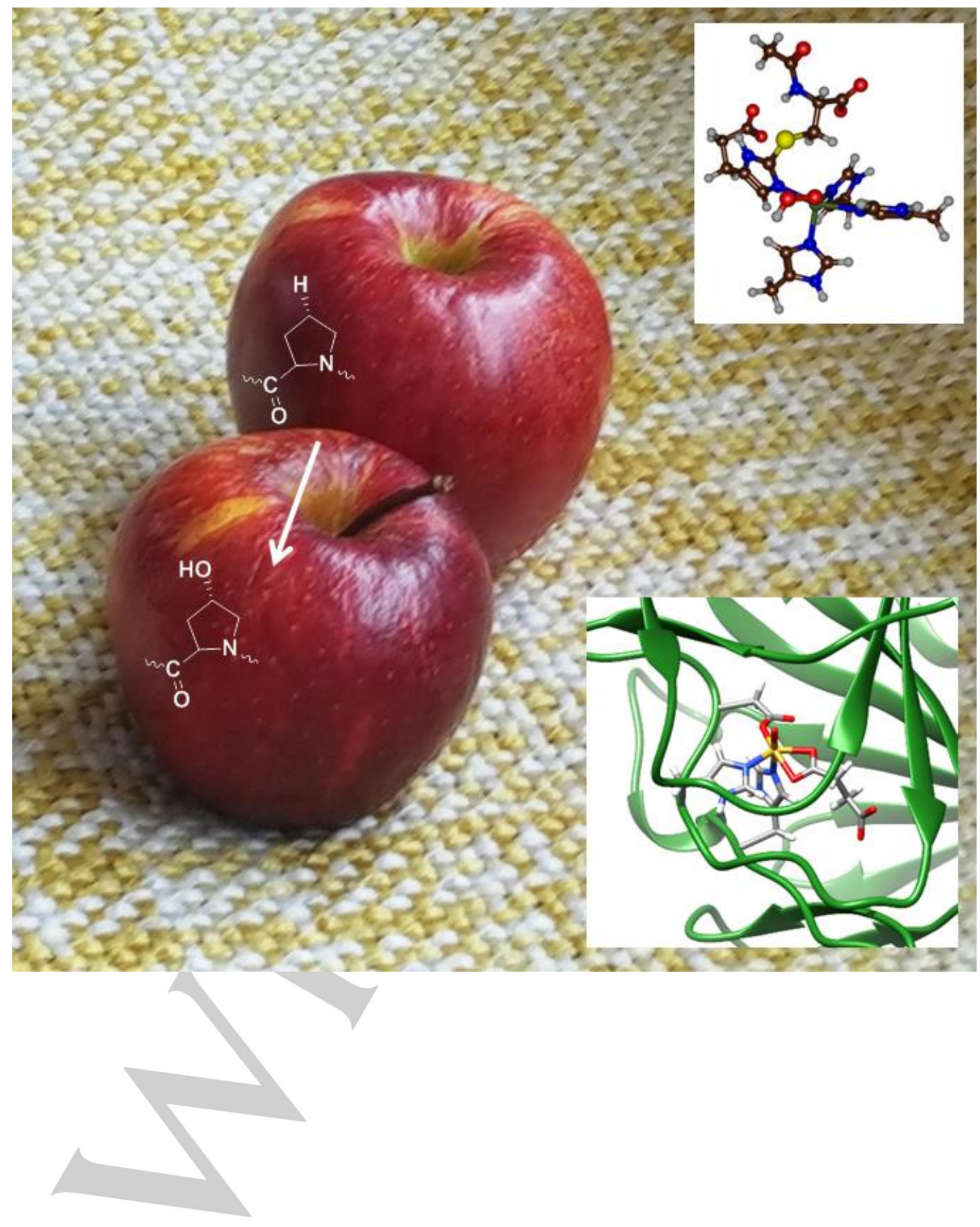

